\title{
BURR FORMATION AT THE INTERFACE DURING BI-MATERIAL ORTHOGONAL CUTTING
}

\author{
C. Poissenot-Arrigoni ${ }^{1 *}$, G. Fromentin ${ }^{1}$, G. Poulachon ${ }^{1}$, B. Marcon ${ }^{1}$, C. Legrand ${ }^{1}$ \\ ${ }^{1}$ Arts et Métiers Institute of Technology, LaBoMaP, UBFC, HESAM, F-71250 Cluny, France \\ ${ }^{*}$ Corresponding author; e-mail: corentin.poissenot@ensam.eu
}

\begin{abstract}
To reduce the size of exit burrs induced by broaching, it is possible to use a low value martyred part clamped to the functional one on the tool exit side. Thence, this research work deals with an in-situ analysis of the burr formation at a bi-specimens interface in orthogonal cutting configuration. New mechanisms of burr formation at the interface formed by Inconel 718 and cast iron specimens are identified. In addition, a post-machining study is carried out to quantify the burr size obtained with and without the martyred part.
\end{abstract}

\section{Keywords:}

Burr formation; Bi-material

\section{INTRODUCTION}

In the aerospace industry, parts are subjected to drastic specifications. For example, the turbine disks specification requires that the manufacturing method ensure controlled burrs sizes, for reasons of mechanical properties. To respect this specification, a few manufacturers machine turbine disks by broaching, because this one enables to obtain complexes shapes with high surface quality. In view to reduce the exit burrs size induced by broaching, which is the only critical burr type of this manufacturing process, it is possible to use a martyred part, clamped to the functional one on the tool exit side.

In the case of the manufacturing process cannot respect specifications for the burr size, an additional and expensive deburring operation is necessary which implies time consuming and supplementary production costs. Therefore, the control of burr size is a huge challenge, which improving the quality of parts produced and reduce costs of production.

Standard [NF ISO 13715 2000] defines burrs by their sizes and more precisely by two distances: the burr height and the burr width. Burrs induced by machining operations have largely been studied in the past in milling and in drilling [Bourlet et al. 2016], [Dornfeld et al. 1999]. In case of roll over burrs formation, some phenomenological burrs height model are proposed [Bourlet et al. 2016], [Kumar et al. 2003]. Nonetheless, the knowledge of burrs formation mechanisms and their shapes prediction is remaining challenging.
Many different burrs classifications, for different manufacturing processes, are present in the literature giving general types in relation to their shape [Da Silva et al. 2016], [Da Silva et al. 2015] [Chern 2006]. [Gillespie et al. 1976], [Régnier et al. 2018] extend and improve those burrs description by associating the burrs shapes with their location on the part after orthogonal cutting. This approach is interesting because it links formation mechanisms and burrs shapes with their localization on the part. As previously said, in broaching, only exit burrs are critical. In this category, [Régnier et al. 2018] distinguishes two types of burrs: the exit burr with and without chamfer. In addition, [Hashiruma et al. 1999] proposes burr formation mechanisms, where the chamfer generation is controlled by the brittleness or ductility property of the material.

In another hand, [Régnier et al. 2018] shows that in a sole material, it is possible to see exit burrs with and without chamfer depending on the cutting conditions and the tool geometry. Moreover, the authors show that the history could have an influence on the presence of chamfers. At the end, it seems that burrs formation mechanisms are complex and are not studied in the known literature at a bispecimens interface.

From a modeling point of view, the calculation of burrs size is a big issue, because burrs formation mechanisms are very complex [Rénier et al. 2019]. Indeed, many different burrs morphologies exist; they are induced by different phenomena and specific to a machining operation. Therefore, the simulation of burrs size at a bi-specimens interface, despite of its apparent simplicity, is actually a 
huge challenge. For instance, to include the martyred part influence in the modelling, it could be necessary to take into account a wide range of parameters such as the contact pressure and the surfaces contact quality at the bispecimens interface, in addition of the required parameters to calculate the burrs size of the functional part.

In the present work, an in-situ study of the burrs formation, in orthogonal cutting, at an interface formed by two specimens is proposed. The aim of this study is to obtain experimental data and a first analysis, which could be later used to improve a burrs formation numerical model, for predicting the burrs size at a bi-specimens interface in orthogonal cutting. In an industrial point of view, a numerica model that predicts burrs size is appreciated, because it allows estimating if the manufacturing process is capable.

\section{EXPERIMENTAL SETUP}

\subsection{Orthogonal cutting setup, samples interface observation, and cutting forces measurement}

The orthogonal cutting was performed during a planning operation along the $\mathrm{x}$-axis of a DMG DMC $85 \mathrm{VL} 3$-axis milling machine (embedded with linear motors). A specific sample-clamping device has been specially designed for this experimentation, in order to clamp together two parallelepiped specimens, with an optimal alignment between two side faces of samples. Furthermore, this device allows setting a variable and controllable contact pressure at the interface formed by the two parts to study its influence on the burr formation. The side of the interface has been observed using a high-speed CCD camera Photron FASTCAM SA-Z, with a $\times 20$ Mitutoyo telecentric lens providing a spatial resolution of $0.86 \mu \mathrm{m}$. Tab. 1 summarizes the camera settings and Fig. 1 shows the orthogonal cutting setup in the machining center and details concerning the samples clamping apparatus.

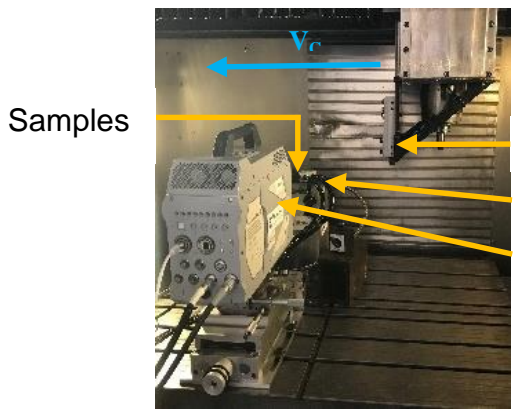

Tool

Liahts

Camera

(a) Global view.

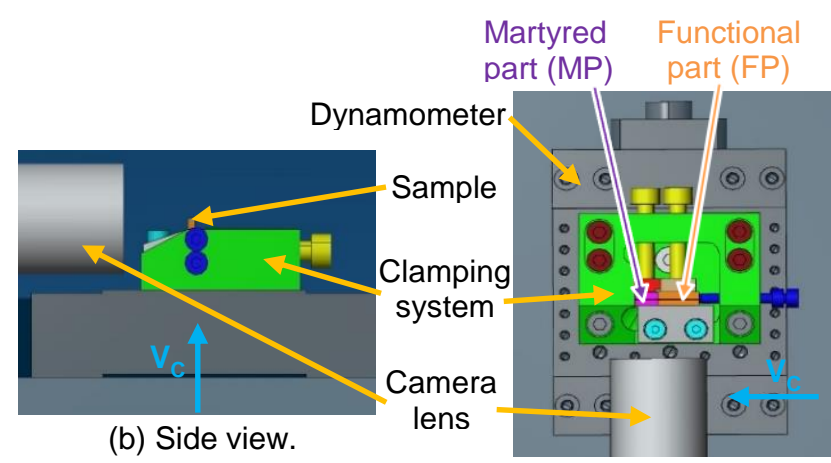

(c) Top view.
Fig. 1: Experimental setup of the orthogonal cutting test:

(a) Global view (real); (b) Side view (Computer Aided Design), (c) Top view (CAD).

Tab. 1: Interface observation high-speed camera settings.

\begin{tabular}{ll}
\hline PARAMETERS & VALUES \\
\hline CCD sensor resolution & $1024 \times 1024$ pixels \\
Lens magnification & $\times 20$ \\
Working distance & $20 \mathrm{~mm}$ \\
Depth of field & $1.6 \mu \mathrm{m}$ \\
Observation window & $878 \times 878{\mu \mathrm{m}^{2}}^{2}$ \\
Spatial resolution & $0.86 \mu \mathrm{m}$ \\
Frame rate & $10000 \mathrm{frames} / \mathrm{s}$ \\
Shutter & $1 / 20000 \mathrm{~s}$ \\
\hline
\end{tabular}

\subsection{Cutting tool and machined specimens}

Specimens materials used for this study are composed of Inconel 718 and cast-iron. A particular attention was paid to obtain the highest possible interface quality, but also regarding the images quality recorded by the camera. Thereby, specific geometric specifications were required during the specimens manufacturing, and each contact areas forming the interface were polished.

The selected tool was in high-speed steel (HSS), with a cutting edge inclination angle $\left(\lambda_{s}\right)$ of $5^{\circ}$ and a cutting edge radius $\left(r_{\beta}\right)$ of $10 \mu \mathrm{m}$. The cutting edge inclination angle $\left(\lambda_{s}\right)$ of $5^{\circ}$ was selected in order to drive the eventual lateral burr visible on the camera, toward the opposite face of the observation one.

For the cutting conditions, a constant cutting speed $\left(\mathrm{V}_{\mathrm{c}}\right)$ of $2 \mathrm{~m} / \mathrm{min}$ and two cut thicknesses (h) of 30 and $50 \mu \mathrm{m}$ have been chosen to obtain continuous chips in Inconel 718 specimens.

A specific design of experiments (presented in Tab. 2) has been conducted, to study the influence of the martyred part (MP) material, the cut thickness and the contact pressure at a bi-specimens interface, on the burrs size of the functional part (FP). Finally, in order to observe the effect of passes history, it has been chosen to follow 10 consecutive cutting passes.

Tab. 2: Design of experiments

\begin{tabular}{cccc}
\hline $\begin{array}{c}\text { Experimental }^{*} \text { references }^{*} \\
\text { A-II-30m }\end{array}$ & $\begin{array}{c}\text { Bi-specimen work } \\
\text { materials (FP/MP) }\end{array}$ & $\begin{array}{c}\mathbf{h} \\
(\boldsymbol{\mu m})\end{array}$ & $\begin{array}{c}\text { Pressure } \\
(\mathbf{M P a})\end{array}$ \\
\hline B-II-50m & $\begin{array}{c}\text { Inconel 718 / } \\
\text { Inconel 718 / } \\
\text { Inconel 718 } \\
\text { Inconel 718 / } \\
\text { cast-iron }\end{array}$ & 30 & 64 \\
C-IC-30-m & $\begin{array}{c}\text { Inconel 718 / } \\
\text { cast-iron } \\
\text { D-IC-50-m }\end{array}$ & 50 & 64 \\
E-IC-30-M & $\begin{array}{c}\text { Inconel 718 / } \\
\text { cast-iron } \\
\text { Inconel 718 / } \\
\text { cast-iron }\end{array}$ & 30 & 110 \\
F-IC-50-M & 50 & 110 \\
\hline
\end{tabular}

*I standing for Inconel 718, $\mathrm{C}$ for cast-iron, $\mathrm{m}$ and $\mathrm{M}$ respectively for low and high level of contact pressure 


\section{RESULTS AND ANALYSIS}

\subsection{Burr formation mechanisms}

Thanks to the high-speed camera, it has been possible to see two different burrs formation mechanisms, driven by the type of material of the martyred specimen.

When the couple of test parts is formed only by Inconel 718 material, a regular burrs formation was observed, as shown in Fig. 2. Indeed, in this configuration, it was observed that burrs grow linearly in function of the pass number whatever the cut thickness (h). Moreover, the burrs sizes observed were relatively small. For example, after 10 consecutive passes with a cut thickness of $30 \mu \mathrm{m}$ for each pass, the cumulated exit burr size of the functional specimen was only $23 \mu \mathrm{m}$, as shown in Tab. 3 . Fig. 2 shows the bispecimens interface before and after machining.
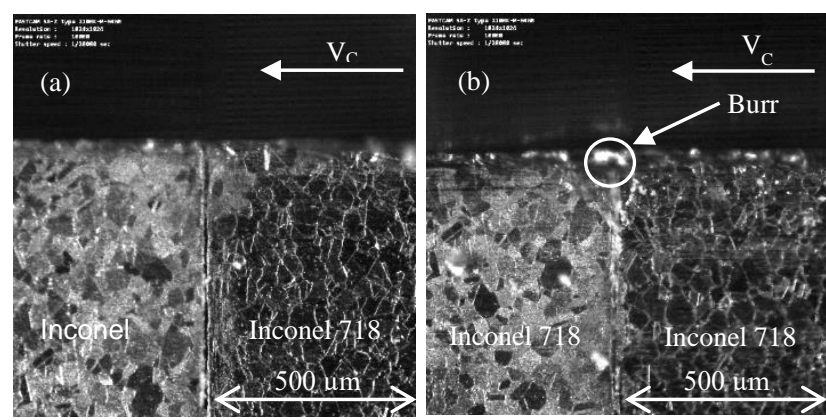

Fig. 2: Burr formation of Inconel 718 / Inconel 718 specimens: (a) initial state before the pass \# 1; (b) after 10 passes, $V_{C}=2 \mathrm{~m} / \mathrm{min}, \mathrm{h}=30 \mu \mathrm{m}$.

In the case of specimens set is formed by Inconel 718 (FP) and cast-iron materials (MP), a specific burrs formation mechanism in three different steps was observed:

- Step 1: To the passage of the tool, the Inconel 718 specimen applied a pressure on the cast-iron part, resulting in a disconnection of a small piece of the castiron specimen. It is important to note that the disengaged cast-iron piece was not snatched out from the part, because it was trapped between the two specimens and the burr of the functional part. Fig. 3 depicts the disconnected cast-iron piece contained between both specimens.
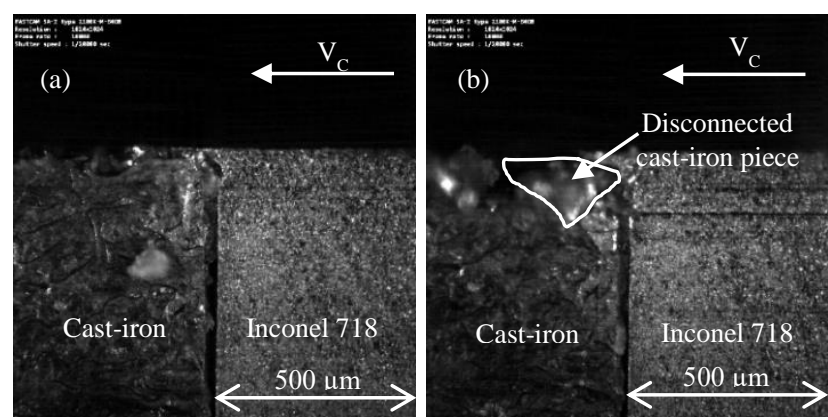

Fig. 3: Disconnection of a cast-iron piece: (a) initial state after the pass \# 6; (b) after the pass \# 7, $\mathrm{V}_{\mathrm{C}}=2 \mathrm{~m} / \mathrm{min}, \mathrm{h}=$ $30 \mu \mathrm{m}$.

- Step 2: The cast-iron piece, which has been disconnected at the Step 1, will be snatched to the part. In this step, two different configurations have been observed:
In the first situation, due to the passage of the tool, the cast-iron piece was snatched out creating a chamfer in the cast-iron and in the Inconel 718 specimens. This configuration has allowed identifying a new burr morphology. Indeed, in the literature, [Gillespie et al. 1976], [Rénier et al. 2018], [Hashiruma et al. 1999], [Rénier et al. 2019] observed exit burrs morphologies are rollover type (without chamfer and with strong positive strain) or tear type (with chamfer and just a little positive strain). However, in this configuration, the observed burrs morphology was with a chamfer and with a strong positive strain; that combination constitutes a new burr morphology never mentioned before. Fig. 4 shows this new burr's morphology, at the interface between two specimens.
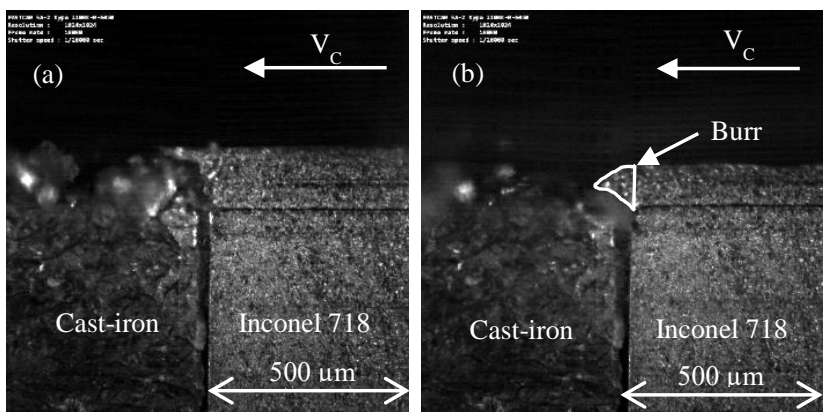

Fig. 4: Pull-out of the cast-iron piece and exit burr with chamfer of the Inconel 718 specimen: (a) initial state after the pass \# 7; (b) after the pass \# $8, V_{C}=2 \mathrm{~m} / \mathrm{min}$,

$$
\mathrm{h}=30 \mu \mathrm{m} \text {. }
$$

In the second configuration, while the cutting tool passed through the interface, the almost detached castiron piece will be snatched out creating a chamfer in the martyred entry part without consequence for the Inconel 718 specimen. The observed Inconel 718 exit burr in this case was a classical rollover burr as depicted in the Fig. 5.

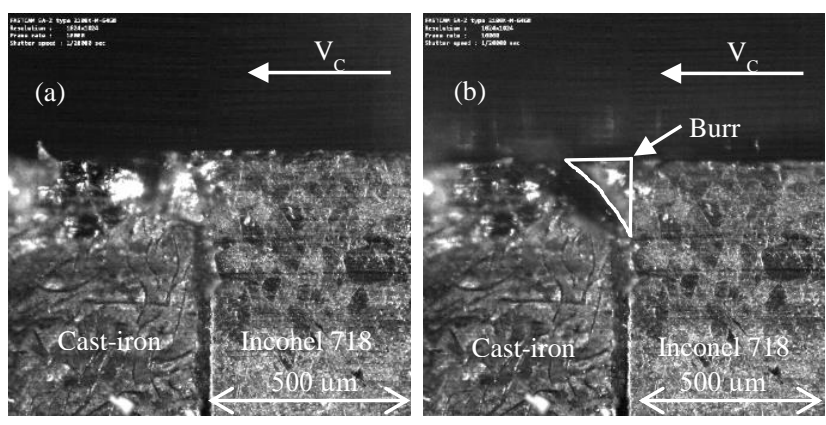

Fig. 5: Pull-out of the cast-iron piece without chamfering the Inconel 718 specimen: (a) initial state after the pass \# 15; (b) after pass \# 16, $\mathrm{V}_{\mathrm{C}}=2 \mathrm{~m} / \mathrm{min}, \mathrm{h}=30 \mu \mathrm{m}$.

- Step 3: In this last stage, the Inconel 718 burr filled the chamfer of the cast-iron specimen. In this step, it has been observed that the Inconel 718 burr behaved like if there was no martyred part. Therefore, the burr of the first specimen undergone a large strain. Fig. 6 shows the large strain of the Inconel 718 burr, which completes the cast-iron chamfer. 

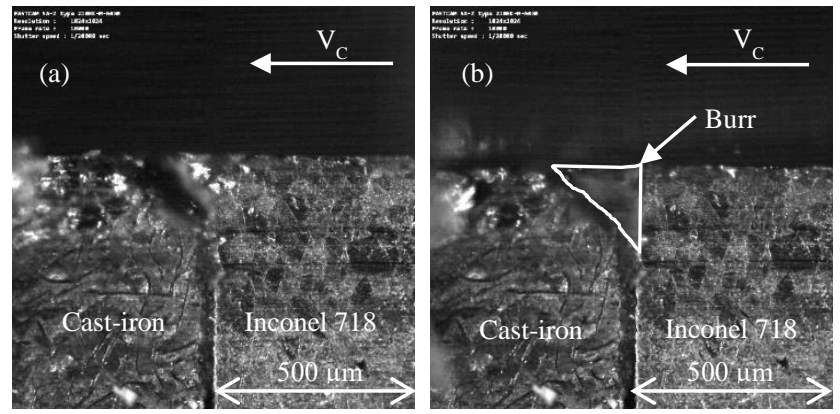

Fig. 6: Large burr deformation that filled the chamfer of the cast-iron specimen: (a) initial state after the pass \# 16; (b) after pass \# 17, $\mathrm{V}_{\mathrm{C}}=2 \mathrm{~m} / \mathrm{min}, \mathrm{h}=30 \mu \mathrm{m}$

At the end, the burrs formation mechanism at an interface formed by Inconel 718 and cast-iron specimens is driven by the brittle behavior and non-cohesive graphite phase in the cast-iron. Therefore, the burrs size of the Inconel 718 specimens did not depend on the passes history, but depended on the progress in the specific burrs formation mechanism. Fig. 7 summarizes the burr formation mechanism observed at the interface formed by Inconel 718 and cast-iron specimens.

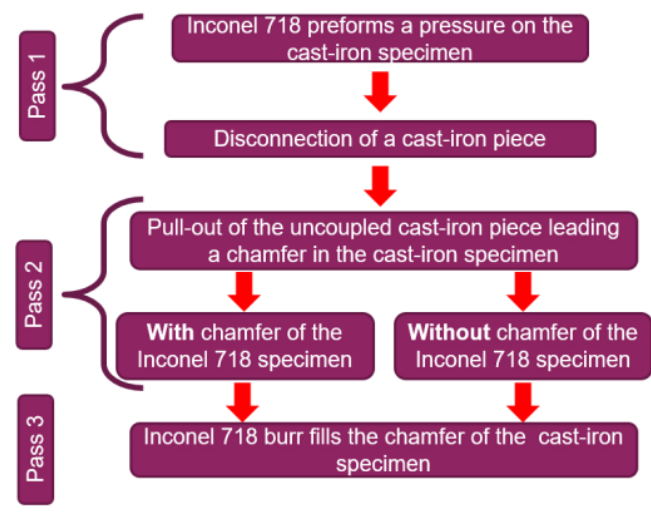

Fig. 7: Burr formation mechanism at the interface of an Inconel 718 / cast-iron specimens.

To conclude on the burr's formation mechanisms at a bispecimens interface, it has been observed that burrs morphology and size depended principally of the material behavior of the martyred specimens. Thereby, in the case of the second specimen was ductile, a regular burrs formation was observed and the burr size depended principally on the cutting conditions and the passes history. Whereas, when the martyred specimen was brittle, a specific burrs formation mechanism driven by the breaking nature of the material was found. In this case, the burr size of the functional part depended on the progress in the burr formation mechanism.

\subsection{Burr size assessment and effect of the interface}

To quantify the influence of the martyred part on the burrs size over the functional one, a study of the final burrs size cumulated after 10 passes has been conducted. For this, burrs sizes have been measured after machining (i.e after 10 tool passes) with an optical microscope Keyence VHX1000. Fig. 8 shows the localization of the measured burrs size and the burrs geometrical descriptors that have been identified. In addition, Tab. 3 presents the cumulated burr size after those 10 passes for Inconel 718 specimens. It is important to note that there is no value concerning the castiron specimens, because the machining did not produce continuous chip in this material, avoiding characterizing the exit burr for these specimens.

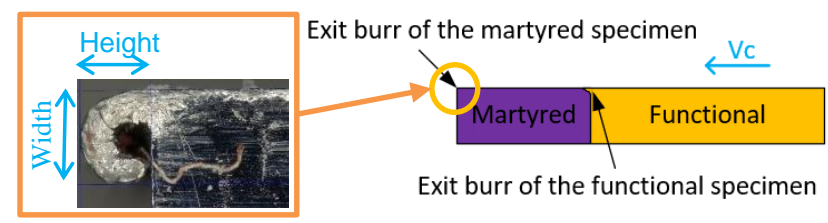

Fig. 8: Burr size after 10 passes.

\section{Effect of the martyred part presence and material}

By comparing the exit burrs sizes of the martyred and the functional specimens, in the same material and with the same experimental conditions, it was possible to estimate the influence of the martyred part on the exit burr size of the functional one. Indeed, given the tool exit side of the martyred specimen was free, it could be considered as an exit burr size reference without martyred part. Therefore, by comparing the exit burrs sizes of functional and martyred parts for the couple A-II-30-m and B-II-50-m, it is possible to say that the presence of the martyred part allowed reducing at least ten times the burr height and five times the burr width. Hence, the martyred part (no value part) acted as a very efficient strategy to reduce the burrs size of the functional part (the part of interest).

In addition, by comparing the exit burrs size of functional specimens for the couples A-II-30-m and C-IC-30-m, and couples B-II-50-m and D-IC-50-m, it was possible to obtain the influence of the material of the martyred part on the exit burrs size of the functional one. Correspondingly, as resumed in Tab. 3, when the martyred part was in Inconel 718 , the burrs size of the functional part was slightly less than two times smaller compared to the martyred part was made of cast-iron. It seems that the martyred part material had a significant influence on the burrs size of the functional part. However, this study requires to be carried out over wider ranges of cutting conditions and material types to quantify this influence and conclude definitively.

\section{Effect of the contact pressure}

Moreover, from Tab. 3, by comparing the exit burrs sizes of the functional specimens for couples C-IC-30-m and E-IC$30-\mathrm{M}$, and couples D-IC-50-m and F-IC-50-M, it could theoretically be possible to estimate the influence of the contact pressure at the bi-specimens interface, on the burrs size of the functional specimen. However, in practice, it does not seem reasonable to draw any strong conclusions about the influence of the contact pressure, since during the experiments carried out, the interfaces qualities were too heterogeneous between different couples of specimens. Therefore, behaviour of the burr of the functional part during the first passes was dictated by the interface quality and not by the contact pressure. Nevertheless, in the prospect of simulating the burrs formation at a bi-specimens interface, this information was useful, because it sustained the need to take into account the quality interface in the model. 
Tab. 3: Cumulated exit burr size after 10 passes.

\begin{tabular}{|c|c|c|c|c|}
\hline \multirow{2}{*}{$\begin{array}{l}\text { EXPERIMENTAL } \\
\text { REFERENCES }\end{array}$} & \multicolumn{2}{|c|}{$\begin{array}{l}\text { FUNCTIONAL } \\
\text { PART }\end{array}$} & \multicolumn{2}{|c|}{$\begin{array}{l}\text { MARTYRED } \\
\text { PART }\end{array}$} \\
\hline & $\begin{array}{l}\text { Height } \\
(\mu \mathrm{m})\end{array}$ & $\begin{array}{c}\text { Width } \\
(\mu m)\end{array}$ & $\begin{array}{l}\text { Height } \\
(\mu m)\end{array}$ & $\begin{array}{c}\text { Width } \\
(\mu \mathrm{m})\end{array}$ \\
\hline A-II-50-m & 20 & 13 & 320 & 421 \\
\hline B-II-30-m & 23 & 62 & 248 & 329 \\
\hline C-IC-30-m & 34 & 72 & & \\
\hline D-IC-50-m & 43 & 125 & & \\
\hline E-IC-30-M & 72 & 89 & & \\
\hline F-IC-50-M & 74 & 100 & & \\
\hline
\end{tabular}

\section{CONCLUSION}

The burrs formation have largely been addressed and modelled in many different machining operations in the past literature. However, there is no known study about the modelling of burrs formation at a bi-specimens interface. This research work presents a preliminary experimental study aiming to simulate the different possible burrs formation mechanisms at a bi-specimens interface.

Firstly, this study has allowed confirming the efficiency of the use of a martyred part, in view to reduce the burrs size of the functional one. Moreover, it confirms the interest to simulate burrs formation at a bi-specimens interface.

Secondly, to get the best possible modelling robustness and accuracy, it could be interesting to take into account, in addition of all the necessary parameters to simulate classic burrs formation:

- The nature of the martyred specimen: Indeed, it has been observed different burrs formation mechanisms, depending on the brittleness or ductility characteristic of the martyred specimen. Moreover, in the case of differences in the characteristics of both materials are really different, the cutting conditions usually optimized for the first material could involve the formation of a discontinuous chip (or even dust in some extreme cases) when machining the second specimen. That could be a problem for the process simulation, particularly when the tool crosses the interface, because the modelling will have to integrate continuous and chaotic chips formation mechanisms. Therefore, it seems interesting to create models able to distinguish if the chip formation is continuous or chaotic, in order to adapt the burrs formation mechanisms according to the cutting conditions.

- The interface quality between the two specimens: Actually, when the interface quality is not perfect, during initial passes, material of the functional part will fill spaces between the two parts by behaving as if there is no martyred part. Therefore, the functional part will be deformed, and the burrs formation will initiate freely. It seems then useful to take into account the interface quality into the modelling to estimate when the burrs formation mechanism starts.

This experimental study has allowed to confirm the interest to model the burrs formation at a bi-specimens interface and to highlight some parameters that could be interesting to take into account in the modelling, in order to obtain accurate simulations.
To finish, in an industrial point of view, although the utilisation of martyred part induces an additional material cost, it allows to significantly reduce burr size and then eventually to remove deburring operation. Therefore, the use of martyred part to control burr size, could reduce production costs in some cases.

\section{REFERENCES}

[Bourlet et al. 2016] Bourlet, C., Fromentin, G., Harika, E. and Crolet, A. Analysis and Modeling of Burr Formation During the Plane Milling of Cast Aluminum Alloy Using Polycrystalline Diamond Tools. Journal of Manufacturing Science and Engineering 2016;138(8):081010.

[Chern 2006] Chern, G.L. Experimental observation and analysis of burr formation mechanisms in face milling of aluminum alloys. International Journal of Machine Tools and Manufacture 2006;46(12-13):1517-25.

[Da Silva et al. 2015] Da Silva, L.C., da Mota, P.R., Da Silva, M.B., Ezugwu, E.O. and Machado, Á.R. Study of burr behavior in face milling of $\mathrm{PH} 13-8 \mathrm{Mo}$ stainless steel. CIRP Journal of Manufacturing Science and Technology 2015;8:34-42.

[Da Silva et al. 2016] Da Silva, L.C., da Mota, P.R., Da Silva, M.B., Sales, W.F., Machado, Á.R. and Jackson, M.J. Burr height minimization using the response surface methodology in milling of $\mathrm{PH} 13-8$ Mo stainless steel. Int $\mathrm{J}$ Adv Manuf Technol 2016;87(9):3485-96.

[Dornfeld et al. 1999] Dornfeld, D.A., Kim, J.S., Dechow, H., Hewson, J. and Chen, L.J. Drilling Burr Formation in Titanium Alloy, Ti-6Al-4V. CIRP Annals 1999;48(1):73-6.

[Gillespie et al. 1976] Gillespie, L.K. and Blotter, P.T. The Formation and Properties of Machining Burrs. Journal of Manufacturing Science and Engineering 1976;98(1):66-74.

[Hashiruma et al. 1999] Hashimura, M., Hassamontr, J. and Dornfeld, D. Effect of In-Plane Exit Angle and Rake Angles on Burr Height and Thickness in Face Milling Operation. Journal of Manufacturing Science and Engineering 1999;121:13-19.

[Kumar et al. 2003] Kumar, S., and Dornfeld, D. Basic Approach to a Prediction System for Burr Formation in Face Milling. Journal of Manufacturing Processes; 2003 ;5(2):127-42.

[NF ISO 13715, 2000] NF ISO 13715:2000(fr) Dessins techniques - Arêtes de forme non définie - Vocabulaire et indication sur les dessins; 2000.

[Regnier et al. 2018] Regnier, T., Fromentin, G., D'Acunto, A., Outeiro, J., Marcon, B. and Crolet, A. Phenomenological Study of Multivariable Effects on Exit Burr Criteria During Orthogonal Cutting of AISi Alloys Using Principal Components Analysis. Journal of Manufacturing Science and Engineering 2018;140, 10-101006.

[Regnier et al. 2019] Regnier, T., Marcon, B., Outeiro, J., Fromentin, G., D'Acunto, A. and Crolet, A. Investigations on exit burr formation mechanisms based on digital image correlation and numerical modelling. Machining Science and Technology 2019; 23-6:925-950. 